\title{
Carmen J. Nielson \\ Private Women and the Public Good: Charity and State Formation in Hamilton, Ontario, 1846-93
}

Vancouver: UBC Press, 2014. 166 pp.

\author{
Patricia Kmiec \\ University of Toronto
}

Private Women and the Public Good examines the development of the political public sphere, liberalism, and state formation in nineteenth-century Hamilton, through a case study of a women's charitable association: the Ladies' Benevolent Society (LBS). The LBS provided assistance that met various community needs at a time when such charity was just becoming the state's concern. Carmen J. Nielson exposes the complex political and social positions of the LBS and their most prominent institution, the Hamilton Orphan's Asylum. The book's central questions revolve around women's participation in the public sphere; however, unlike earlier historians of nineteenth-century women's associations in Canada, Nielson argues that women's organized charitable efforts did not challenge the ideology of gendered separate spheres in any significant way.

Nielson seeks to demonstrate how the emergence of the public sphere, on both political and intellectual levels, was connected to gender, charity, and childhood. Her analysis draws these themes together in a way that effectively illustrates how the power of the ideology of separate spheres was closely connected with a political rhetoric that limited the potential of both ideas about - and actions of - women and men. This detailed account of the efforts of the LBS is based on the organization's records as well as discussions of their work in the local press. Published annual reports of the LBS are carefully considered, not only for their descriptions of the association's activities, but, importantly, as a channel of communication between the organization and its public supporters.

The book traces the Hamilton LBS from its founding in 1848 to 1893 , when emerging state organizations decreased the need for its services. The LBS is introduced through founding member and long-time treasurer, Lydia Jackson. As Jackson 
and her prominent husband Edward settled in Hamilton, his political involvement and her charitable work represented the general trend of the growing young city. In the period leading up to the middle of the century, a handful of white, Protestant, professional men became political leaders while their wives, daughters, and sisters, established a space for themselves in the community through the LBS. The private ties to public men that the women of the LBS had remains central as the analysis moves towards a closer look at the motivation, approach, and activities of the association. The LBS' ideas were grounded in the philosophy of scientific charity and influenced by other Victorian visiting societies.

The book then explores a number of challenges the organization faced, many resulting from the mass wave of Irish Catholics arriving in Hamilton before 1850. A series of public controversies are discussed, including issues that emerged with increased local poverty, and the establishment of Hamilton's St. Mary's Benevolent Society, a Catholic counterpart to the LBS, in 1850. The controversies dealing with the Hamilton Orphan's Asylum were the LBS' greatest struggles, and are explored at length to demonstrate the complex position of the society, as it received some public funds and provided a public good, yet was under the private care of its women members. The tensions began in 1850 , when the LBS approached the city for a $£ 500$ grant to improve the orphan asylum building. A Catholic councilman and his supporters opposed the grant, accusing the LBS of proselytizing to Catholic children. The accusations resulted in increased regulation and surveillance of the asylum by male city officials. The particularities of this case reveal the public rhetoric around the LBS, women's charity, and the public voices needed to defend and validate the work LBS women were doing.

The remainder of the book focuses on the Hamilton Orphan's Asylum and connects ideas and practices about childhood and childcare to the LBS' work with the public. The reasons children were placed in the asylum are addressed. Nielson notes that not all were orphans; many still had at least one living parent. The options available for these children and youth (adoption, apprenticeship, and institutional care) are explored in detail. The author features original accounts throughout. The decline of the Orphan's Asylum, with the implementation of the Children's Aid Act in 1893, and the establishment of Children's Aid Societies, wraps up the discussion. Nielson's analysis clearly demonstrates that when public efforts emerged in the last decade of the nineteenth century few of these strategies and approaches were innovative. In fact, many of the attitudes that informed the Children's Aid Societies, including a "bestinterest of children" philosophy and an emphasis on family reunification, had also shaped the LBS' activities with children from as early as the 1850s.

Private Women and the Public Good is well organized, clearly-focused, and readers who are familiar with nineteenth-century Canadian cities will find it easy and enjoyable to read. The most pleasing sections of this book focus on the Hamilton Orphan's Asylum. This study takes childhood seriously even though it is not explicitly or exclusively investigating it, and that approach will be refreshing for scholars of mid-to-late nineteenth-century Ontario.

Although Nielson's main goal is not to bring to life the women of the LBS in any personal way, the lack of personality is occasionally distracting. A page at the end of 
the first chapter notes a few moments in the lives of a handful of the organization's leaders (mainly, the work of their husbands), but throughout the book women are generally mentioned only by name. For example, it is disappointing to see women like Mary Armstrong Ryerson, who served as the organization's vice-president, mentioned only once, to note her husband Egerton's connections to public education. Furthermore, the white, Protestant women who made up the LBS are generalized throughout, and Nielson is hardly convincing in her claim that "[p]recious few remnants exist to tell us anything about the lives of the women who founded and built this association" (15). Given the brevity of the book, with the shortest chapter at only eight and a half pages, this seems especially striking.

Private Women and the Public Good makes a number of important contributions to our understanding of nineteenth-century Ontario. The direct attention to the themes of gender and childhood make it a welcomed addition to the growing historiography on the public sphere in Ontario that has followed the work of Jeffery McNairn. ${ }^{1}$ This study also provides some stimulating questions for scholars with interests in gender and childhood. Although the book is unusually short, there is no doubt that the questions it raises prove that there is still much more to explore in these areas.

\section{Notes}

1 Jeffrey L. McNairn. The Capacity to Judge: Public Opinion and Deliberative Democracy in Upper Canada, 1791-1854 (Toronto: University of Toronto Press, 2000). 